\title{
9. Applying Three Frames to the Delivery of Public Value
}

\section{Jim Varghese, Director-General, Department of Primary Industries and Fisheries, Queensland}

I recently attended an ANZSOG CEO workshop where I was particularly encouraged and interested in the work of Harvard University academic Mark Moore on public value. Moore (1995) offers the notion of public managers creating public value for society (for the short and long term) for strategic management in Government. Drawing on Moore's definition, public value is understood to be the achievement of favoured outcomes by the use of public resources in the most effective manner available (Moore 1995).

In this presentation, I would like explore the idea of using a management process called the 'Three Frames' to deliver innovative public value. During my public service career, I have had the opportunity to work in a number of different agencies. I have served as Director-General of four Queensland Government Departments - Main Roads, Education, Employment and Training, and Primary Industries and Fisheries. I am also the Government champion for Lockhart River - a remote community in Cape York.

Each department and the community presents its own set of challenges, diversity and opportunities for creating public value. Some significant results for public value ranged from completing roads projects such as the Pacific Motorway in Main Roads to shaping the Learning, Skilling and Work agenda for Employment and Training and the creation of the Lockhart River fishing company.

In a case study by Dr Kerry Brown and Christine Flynn on the Queensland Department of Main Roads, they concluded that:

The integration of relationship-building with high quality technical service delivery (at Main Roads) gives new insight into public sector management strategies, as traditional internal strengths were built on at the same time as efforts to broaden and enhance organisational capabilities in different ways.

In all of these cases, my focus has been on creating the purpose and mission of these organisations to shape their identity.

I developed the Three Frames management process and successfully implemented this in the Government agencies where I have served as Director-General - most recently, the Department of Primary Industries and Fisheries (DPI\&F). 
While it can be described as a management tool, the Three Frames process is not limited to management in a purely business sense. It is a methodology, or a philosophy, that can be equally well applied to personnel management or to the way in which agencies such as my own can deliver on government priorities and meet the many challenges we face daily.

One such challenge was the response to the recent oil spill in Gladstone Harbour where a fuel tanker on a bulk carrier from Korea was ruptured when it was hit by a tugboat in Gladstone Harbour on 24 January 2006. For around 40 minutes, the ship's fuel spilled 25,000 litres of heavy fuel into Gladstone Harbour, creating a slick.

Apart from the immediate environmental impact, this oil spill had the potential to have a long-term economic impact on the local fishing industry contaminating prawns, crabs and fin fish, making them unsuitable for sale, and destroying local breeding grounds. The immediate environmental and economic impact would also have significant social implications for the local community.

The Department of Primary Industries and Fisheries was charged with ensuring that the impact on the fishing industry was minimal and that the local community supported the actions the department would take to remedy this situation. Our response was based on the Three Frames approach with the aim of creating public value. This involved having a clear understanding of the desired outcome, connecting the people and organisations involved and identifying problems and responses together.

This approach can be applied on our general business operations. Each day, the operations of public sector operations consume public resources and produce real consequences for society. Moore provides the idea of a strategic triangle with the intersection of legitimacy and support, public value and organisational capabilities as essential elements in this outcome. He challenges public managers to imagine and articulate a vision of public value that can command legitimacy and support and is operationally 'doable' in the domain for which they have responsibility.

This framework helps us, as public managers, to connect what we believe is valuable, and requires public resources, with improved ways of understanding our public value. I believe that there is a strong congruence between Moore's premise and the Three Frames methodology - of performance, relationships and alignment to create innovative public value and leadership of strategic management in Government.

\section{The Three Frames}

The Three Frames approach consists of three interacting, learning frames, being:

- the Relationship Frame; 
- the Performance Frame; and

- the Alignment Frame.

\section{The Relationship Frame}

The aim of the relationship frame is to build and sustain a safe, non-threatening environment in which people feel able to share information including their thoughts, feelings and values honestly with others.

This frame of reference acknowledges the individuals and relationships within the system and also recognises these within social capital theories. Robert Putman put it this way:

Stocks of social capital, such as trust, group norms, and self help networks, tend to be self reinforcing and cumulative. Successful collaboration in one endeavour builds connections which makes further collaboration possible.

The Relationship Frame helps individuals and groups develop a rapport with others, providing the best environment to solve problems, support each other and to achieve desired outcomes.

\section{The Performance Frame}

The Performance Frame looks at what we want to achieve and provides a clear and measurable picture of what we want, and need, to achieve to meet our goals. In a business management context a balanced scorecard approach can be used to set goals and accurately monitor performance. In the macro sense 'government' expectations are the benchmark. In this frame we need to determine what we as a department want to achieve and the way we want to achieve it.

\section{The Alignment Frame}

The Alignment Frame looks at the relationship between or within organisations and their members, and identifies any blockages that are stopping them from achieving their goals as set in the performance frame. The alignment frame accepts as its basic premise that poor alignment of relationships creates barriers to the achievement of an organisation's goals.

The Alignment Frame acknowledges the importance of both the organisation and the individual, and in so doing, highlights the importance of each to attaining of the goals of the other.

The Three Frames approach has been, in my view, the critical success factor in delivering what the Government requires from my agency. Effective relationships breed productive connections, both for the individual and for the organisation. Through relationships, information is created, transformed and passed on, and confidence and empowerment are built. This spirit of connectedness 
(relationships), coupled with a supportive environment that brings commonality of purpose (alignment) for all parties, will ensure that departmental delivery is aligned to government expectations (performance).

The Three Frames supports Moore's idea that public managers are seen as explorers (through the alignment frame) who with others (in the relationship frame) seek to discover, define and produce public value (the performance frame). I see the strategic triangle as an 'organic' system. Our reliance on mechanistic and controlling approaches to leadership and management stand in the way of innovation and effective leadership over participatory and self-organising processes. There is an intrinsic value in participation.

Moore's strategic triangle neatly overlays with this and the Three Frames. As Moore suggests: 'Managers should interact with the political system not simply through the medium of their mandated purposes but instead through more continuous and interactive dialogue'.

The Three Frames supports participation and engagement through dialogue, in a committed and consistent manner, to respond effectively to issues.

The features of dialogue are:

- welcoming multiple viewpoints and maximum interaction;

- behaviours that encourage co-operation with and acceptance of others;

- talking and learning about shared issues which effect public value; and

- inquiry, exploration and participation with the authorising and un-authorising environment.

Dialogue creates and recognises the humanised social systems of internal and external relationships which exist in all authorising environments. I believe the government's response to the Gladstone oil spill is one example where Three Frames has been successfully applied to support a dialogue-based process to enhance public value.

\section{Legitimacy and Support}

As mentioned previously, the Gladstone oil spill had economic, social and environmental consequences for public value. It had the potential to generate public and political controversy. A wide range of interests were affected, including local and State government, industry, environmental groups and the local community, among others.

Commercial fishermen, seafood processors and local seafood retailers were worried that their industry would be devastated, with potential long-term impacts on fishing stocks. Environmentalists worried about the impact on sensitive seagrasses and mangroves, as well as local dolphin and dugong populations. The wider Queensland community was concerned about health and safety issues in consuming seafood from the Gladstone area. 
The Gladstone community was concerned about the impact on its seafood industry. The Queensland Seafood Industry Association was worried about the impact on consumer's perceptions of wild caught product.

The public value lay outside the scope of one public organisation. It involved Queensland Transport who were responsible for cleaning up the oil spill; the Environmental Protection Agency who were responsible for managing the impact on wildlife and water quality; Queensland Health who administer 'The Food Act' and is responsible for ensuring the seafood is safe to eat; Primary Industries and Fisheries who is responsible for the local fishing industry; The Premier and Cabinet who is responsible for the government's response to this incident and the local council.

DPI\&F facilitated the co-ordination of these diverse interests and perspectives.

\section{Organisational Capabilities}

I facilitated a learning circle dialogue in Gladstone with key players in the authorising environment to respond to the issue. The objective of the dialogue was to commit to a course of action with specified outcomes, responsibilities and timeframes. The result of the dialogue-based learning circle was a commitment to a course of action by a range of groups with multiple public value dimensions. We convened the learning circle in the place where the event occurred in order to empower local groups with a perceived stake in the decision-making affecting their community. While we used the learning circle in this particular instance, I have developed a range of techniques to support the Three Frames in delivering innovative public value.

These include:

- Achievement Planning - a system for creating individual staff achievement plans to link staff outcomes, results and behaviours to priorities and directions that maximise public value (DPI\&F is also introducing the Leadership Impact tool by Human Synergistics to measure leadership impact of our Executive and senior leaders);

- Dialogues for Action Forums - engagement and dialogue with external stakeholders;

- Three Frame Audits - engagement and dialogue with internal stakeholders;

- Strategic Conversations - face-to-face dialogues between the Director-General and groups of staff to discuss a current business issue;

- Management Learnings - a dialogue to reflect, learn and improve from an activity or event; and

- Director-General Chat-line-an on-line communication system for staff to engage with the DG by posting direct messages/questions and answers to business issues and issues of public value. 
There have been over 60 Three Frame-based engagement sessions used in DPI\&F to interact in a meaningful way with our internal and external stakeholders. This is also being recognised internationally with DPI\&F currently being short listed as a semi-finalist in the Commonwealth Awards for Public Administration and Management for its citizen engagement work.

\section{Conclusion}

In the case of the Gladstone oil spill, in February 2005 we were able to inform the commercial seafood operators that their catches were cleared for market. As promised during the Learning Circle, the department collected more than 100 seafood samples from commercial operators. All of the samples were tested by Queensland Health and showed that the seafood was suitable for sale. Also as promised, the affected area will continue to be monitored over the next five years to ensure there are no long-term effects.

DPI\&F is working in concert with stakeholders, the Gladstone City Council, the Central Queensland Ports Authority and others to rebuild the reputation of the city's seafood. This is just one example of where the Three Frames gives a simple heuristic tool for public managers to address performance, relationships and alignment to enable and deliver corporate strategy and create public value.

\section{References}

Moore, M H (1995), Creating public value: Strategic Management in Government, Harvard University Press, Cambridge Massachusetts.

Wheatley, M (2005), Finding our way: Leadership for an uncertain time, Berrett-Koehler Publishers, San Francisco. 